\title{
The effect of entrepreneurial orientation on innovation performance: The mediation role of
} learning orientation on Kuwait SMEs

\author{
Adel TH Q Shahera* and Khairul Anuar Mohd Ali ${ }^{\mathrm{b}}$
}

${ }^{a}$ Researcher, UKM-Graduate School of Business, National University of Malaysia, 43600 Bangi, Selangor, Malaysia ${ }^{b} U K M$-Graduate School of Business, National University of Malaysia, 43600 Bangi, Selangor, Malaysia

\section{H R O N I C L E}

\section{Article history:}

Received: June 26, 2020

Received in revised format:

June 302020

Accepted: July 26, 2020

Available online:

July 26, 2020

Keywords:

Entrepreneurial Orientation (EO)

Learning Orientation (LO)

Innovation Performance (IP)

Small and Medium Enterprises

(SMEs)

\section{A B S T R A C T}

SMEs play a critical role for the economic growth of nations by providing the opportunity for individuals to develop their skills and to be self-employed. SMEs are flexible and are able to quickly acclimatize to the factors affecting supply and demand. In todays' rapidly changing business environment, SMEs are faced with difficult challenges to effectively implement the practices that are frequently adopted by larger business rivals. This study will discuss the concept of entrepreneurial orientation, innovation performance, and learning orientation in the context of SMEs in Kuwait. This study assumes that Entrepreneurial Orientation has both direct and indirect impacts on Innovation Performance (IP) through the mediating role of learning orientation. This study used quantitative methods to investigate and test the hypothesis that the association of entrepreneurial orientation with innovation performance was mediated by learning orientation. The target population in the present study is the owners and CEOs of SMEs in Kuwait, and the stratified random sampling method was used to select 221 participants. This study used a structured questionnaire containing close ended questions to gather the data. The data was analyzed using the partial least square structural equation modelling (PLS-SEM). Results of the analysis show that learning orientation played a partial mediating role in the association of entrepreneurial orientation with innovation performance.

\section{Introduction}

In recent years, researchers throughout the world have been showing increased interest in Small and Medium Enterprises (SMEs) due to their significant role in the economic expansion of countries (Yauri \& Bankanu, 2008). In view of this fact, there is an urgent need for SMEs throughout the globe to implement a high degree of innovation in order to be able to continue to make the critical contribution in establishing a competitive private sector and to promote economic development as well as to generate employment. It is evident that within this world of constant changes, SMEs struggle to successfully implement practices that are more commonly used by their larger competitors SMEs in the state of Kuwait play a very important role for the development of the economy, as they stimulate self-employment and skills development, characterized by flexibility and rapid adaptation to supply and demand factors (Abu-Aisheh, 2018). In todays' fluid business climate, SMEs are faced with serious challenges in the attempt to adopt the practices that are frequently implemented by larger businesses. Larger organizations have better capabilities to implement innovation due to their superior capital resources, technological capabilities, substantial and dedicated teams, and advanced instruments. SMEs in Kuwait play a critical role in the country's economic growth by promoting competency development and independent workers; these SMEs are flexible organizations that have the ability to quickly adapt to the factors influencing supply and demand. SMEs create jobs and recruit employees during economic reforms and expand to fulfil the higher demand at times of economic boom; SMEs are also in the position to quickly * Corresponding author. Tel.: + 96599511642

E-mail address: zp03484@ @iswa.ukm.edu.my (A. T. Q Shaher) 
respond to market opportunities, and thus are able to make significant contribution to the different sectors of the business (Bloch \& Bhattacharya, 2016). Despite these evidences, SMEs throughout the globe in general, and in Kuwait in particular, are facing increasingly complex challenges (Bouazza, 2015). Furthermore, the extent of entrepreneurship and innovation in Kuwait is still lagging behind most other countries in the world. Thus, there is a pressing need to better understand the entrepreneurship phenomenon and the innovation processes in SMEs in order to be able to make a transition in an innovationdriven economy and to help SMEs improve their performance (Wonglimpiyarat, 2015). The learning process adopted by SMEs facilitates the development of knowledge, skills and abilities that are required by the SMEs to carry out their socioeconomic functions (Ratnawati et al., 2018). Thus, LO is an important element in the effort to enhance innovation performance. Learning orientation is important in the acquisition of knowledge and the application of the acquired knowledge to achieve better performance (Boso et al., 2012; Jha \& Bhattacharyya, 2013). Recent studies have shown that modern organizations require a strong LO to gain competitive advantage. LO influences the innovativeness of a firm, which in consequence determine the firm's performance (Roger et al., 2002). Therefore, LO has the ability to help an organization implement effective innovation and thus improve their performance (Huang \& Wang, 2011; Donate \& de Pablo, 2015; Beyene et al., 2016; Kellermanns, et al., 2016). In this vein, the performance of a firm is influenced by EO and LO; it is worth noting that the impact of EO on performance is indirect and is mediated by LO. Most other studies (Jalilvand et al., 2018; Genc et al., 2019; Kollmann \& Stöckmann, 2014) did not address the relation of EO with innovation performance despite the implementation of LO by the firms. Therefore, this study will discuss the concept of Entrepreneurial Orientation (EO), Innovation Performance (IP) and Learning Orientation (LO) in the context of SME in Kuwait.

\section{Literature review}

\subsection{Entrepreneurial Orientation}

Entrepreneurship is the activity of setting up a new business or an enterprise, or relaunching a current business in an attempt to take advantage of newly identified possibilities (Lechner \& Gudmundsson, 2014). In principle it is a proactive stance which promote taking the responsibility for the problems faced by society and viewing them as opportunities, and assuming the risks in resolving the problems (Huggins and Thompson, 2015). Thus, the development of entrepreneurship necessitates a suitable framework which inspire individuals to take the necessary measures to begin small and medium businesses and to increase the possibilities for achieving success (Koch, 2011). EO is a strategic orientation implemented at the enterprise level and it encompasses the practices adopted by the enterprise to formulate strategies, the administrative philosophies, and the behaviours that are inherently entrepreneurial (Anderson et al., 2009). EO is one the most frequently investigated and recognized research construct in the literature on entrepreneurship. In the present day, fluid global environment, business organizations are required to be entrepreneurial in assessing a business environment in the event that it is essential for ensuring business growth and business survival (Renko et al., 2009). The fast-evolving business climate that resulted from innovation and the accompanying shorter product life cycle has necessitated for enterprises to think creatively in generating new ideas, products, and forms whilst adapting the rapid change taking place (Rhee et al., 2010). The intense global competition and rivalry highlight the need for businesses to be innovative in the attempt to gain a competitive edge (Rubera et al., 2012). The EO conceptualized by Miller and Friesen (1982) consists of three dimensions and used commonly in the literature namely; (1) Innovativeness which means Preparedness to carry out innovation, come forward with new and creative ideas, conduct experiments to develop novel goods and services and processes (Lechner \& Gudmundsson, 2014), (2) Proactiveness Identify opportunities, achieve progress by coming forward with novel goods and services, and predict potential demand in order to effect change and structure the environment (Kwak, 2013; Khan \& Khalique, 2014), (3) Risk-taking Inclination to take bold actions. Explore emerging and unknown markets, use a large amount of resources to take risks, and secure a large amount of loan (Kellermanns, et al., 2016; Kajalo \& Lindblom, 2015).

\subsection{Learning Orientation}

In the recent decades, organizational learning has been established to be a significant element in ensuring that organizations are able to achieve competitive edge and have the capability to learn at a faster rate than competing organizations; in a nutshell, organizational learning is the root cause of a sustained competitive edge. Hence, organizations that operate under complex business environments with a high level of uncertainty should rely on learning orientation as one of the effective strategic orientations in order to achieve organizational excellence. (Eshlaghy \& Maatofi, 2011). LO is the degree that organizations acquire and exchange information regarding market developments, customer demands and requirements, and new technological advancements to manufacture new goods and services with superior quality than those produced by rival businesses (Kharabsheh et al., 2017). It is well-known that without learning prospective business people would not be able to take action to establish an enterprise. Even if they were inspired to take measures, they would probably end up feeling discouraged due to the lack of exposure to opportunities or due to the inability to get the help they require to successfully initiate a new business. Despite having the required technical skills, they are very unlikely to succeed in their business ventures if they do not have the necessary business and management expertise. (Koch, 2011). Organizational learning can produce many benefits, for instance a successful introduction of new products, customer retention, higher revenues, and provision of the higher quality desired by the customers. Organizational learning also provides the organizations with greater flexibility which in consequence allows the organizations to swiftly respond to the new opportunities and distresses in the environment (Beyene et al., 
2016). The three major dimension of LO are commitment to learning, a shared vision, and open-mindedness (Beyene et al, 2016). The learning commitment of an organization is manifested in the emphasis given to learning and its sustained commitment to learning. The open-mindedness of an organization is the degree of its readiness to adopt change and new methods of conducting business. According to Donate and De Pablo (Donate and de Pablo, 2015), the open-mindedness of an organization is reflected in its preparedness to challenge the established assumptions and beliefs and to abandon these assumptions as appropriate. The establishment of a shared organizational vision provides guidance with regard to the knowledge acquired by an organization and how those knowledges are acquired. (Calantone et al., 2002). A description of the three dimensions are given below.

\section{Shared vision}

Shared vision is the focus given by all individuals to the learning that would bring about higher levels of energy, dedication and resoluteness. A shared vision is able to improve the quality of learning whilst ensuring harmony throughout the organization (Eshlaghy \& Maatofi, 2011).

\section{Commitment to learning}

The commitment of an organization to learning is the extent that the organization regard learning as worthwhile and therefore make the endeavour to encourage learning whilst also establishing and nurturing a climate that encourage learning (Alegre and Chiva, 2008).

\section{Open-mindedness}

Open-mindedness is the critical assessment of the organization's day-to-day operations and the adoption of fresh ideas. Put differently, it is an approach adopted by organizations to abandon the current knowledge or the redundant assumptions and habits since the knowledge could be a major hindrance which prevent the organizations from adopting the vision and the processes that are required to facilitate innovation and change (Eshlaghy \& Maatofi, 2011).

\subsection{Innovation Performance}

Innovation is one of the catch-word of the present-day society. Most people deem innovation to be necessary for individuals and organizations. As an example, people insist that organizations must be more ingenious in dealing with organizational and socioeconomic issues (Demircioglu \& Audretsch, 2019). Innovation is a complicated concept that intersect with a number of other relevant concepts, for instance technology, creativity, and change. The investigation on innovation covers a number of research areas such as business, economics, engineering, and public administration. Researchers have been investigating innovation at varying level of analysis, including individual, group, organization, industry, and economy. Organizational innovation is the examination of innovation in the field of business and public organizations (Le Bas et al., 2015). Innovation is related to the economic possibilities brought about by emerging technologies, goods, services, processes, and business models. Innovation does not occur in isolation; instead it is an orderly and streamlined process which necessitates stringency, and can be acquired and implemented. Therefore, in order to succeed in making innovation an entrepreneur must be far-sighted and seek out the reservoir of innovation and harness them (Hisrich \& Kearney, 2014). The types of innovation differ and is influenced by the object, sector and scope or the magnitude of innovation, each innovation has its own traits and characteristic. Among the types of innovation performance are Product innovation, Process innovation, Organizational innovation, technological innovation, and market innovation (Carayannis \& Grigoroudis, 2014). The elements of an innovation are divided on the basis of specific dimensions, and are therefore a developing process through which greatly enhanced new goods or processes replace the current goods or services. among the approaches and dimensions that improve innovation performance are (Teece et al., 2016):

\section{Product Innovation}

Product innovation is the introduction of new goods/services or making considerable enhancement to the current goods/services (Polder et al., 2010). Product innovation means producing a new product or manufacturing a considerably enhanced products in terms of their characteristics, intended purpose, software, ease of use or components and material. Reguia (2014) contended that product innovation is not a new phenomenon which emerge out of the blue in the contemporary times. It has been occurring for thousands of years and has been shaping the human lives.

\section{Process Innovation}

Process innovation is making significant enhancements to the methods of manufacturing and logistic support or making considerable enhancement in supporting activities such as purchasing, accounting, maintenance and computing (Polder et al., 2010). Process innovation is characterized by enhanced processes in the manufacture of products and provision of services. 
Even though the final product may not be altered, the benefits in the manufacturing process has the effect of boosting productivity and reducing expenditure. As an example, automobiles are manufactured using robots instead of human workers (Proctor, 2018).

\section{Marketing Innovation}

Marketing innovation is the adoption of new marketing approaches that are characterized by substantial changes in terms of packing, design, presentation, advertising and pricing strategy (OECD, 2005). Marketing innovation seeks to increase turnover and market segment as well as to introduce new markets (Polder et al., 2010). Marketing innovation brings about considerable enhancements in certain marketing elements, including product, price, advertising, distribution and market (Lopes et al., 2016).

\section{Hypotheses development and Conceptual Framework}

\subsection{The association of Entrepreneurial Orientation with Innovation Performance}

Previous studies have acknowledged the significance of EO as a measure when exploring market opportunities and its role in enhancing firm performance (Fairoz et al., 2010; Frank et al., 2010). EO includes the methods, creativity, innovation, practices, and risk-taking adopted by managers to make strategic decisions and to act entrepreneurially (Jalilvand et al., 2018; Real et al., 2014), these components of EO is expected to positively impact innovation performance in SMEs. Hence, the relationship between EO-IP needs to be explored in the context of SMEs in different countries (Zehir et al., 2015). Even though the association of EO with firm performance has been extensively examined theoretically and empirically (Amin et al., 2016; Vega-Vázquez et al., 2016), there is a dearth of studies which examine the impact of EO on SMEs innovation performance (Zhai et al., 2018). There is also a need to scrutinize the findings of the studies which investigate the impact of the EO adopted by SMEs on innovation performance (Jalilvand et al., 2018; Zehir et al., 2015). To the best of the researcher's knowledge, the understanding of the manner in which EO influence the innovation performance of SMEs is not sufficient even though EO has been acknowledge to be an importance indicator of SMEs performance. Although the results of the studies carried out by Zhai et al. (2018) and Jalilvand et al. (2018) provided limited insight into the relationship in context of SMEs in China, Iran and Taiwan, the different EO construct and the scale of innovation performance in different industries may differ between countries (Amin et al., 2016). Thus, the present study seeks to closely scrutinize the EO adopted by Kuwait SMEs and its impact on innovation performance. With this, it is posited that:

$\mathrm{H}_{1}$ : Entrepreneurial orientation has a significant effect on the innovation performance of SMEs in Kuwait.

\subsection{The association of Entrepreneurial Orientation with Learning Orientation}

The literature has shown that organizations may adopt two strategic orientations, EO and LO, which may have an impact on each other (Allameh \& Khalilakbar, 2018; Hernández-Linares et al., 2018). In fact, researchers have noted that the process through which LO and EO operate is not a simple one; instead each construct has a complex relation with performance (Hernández-Linares et al., 2018). While both EO and LO are closely related to each other, some researchers considered LO to be a vital antecedent of EO while other researchers contended that EO is a consequence of LO, although there is little consensus in justifying the relationship between the two. For example, Aloulou (2018) conducted a study involving 230 Saudi firms and has determined that the relation of EO with LO is significant. Similarly, Allameh and Khalilakbar (2018) conducted a study involving Iranian SMEs and found that LO is positively influenced by EO. In contrast, Hernández-Linares et al. (2018) contended that LO has the ability to improve EO and that there is a significant and positive association of LO with EO in Spanish family businesses. Similarly, Ebrahimi et al. (2018) have shown that LO has a positive effect on entrepreneurship of SMEs. Kakapour et al. (2016) conducted a study on 130 Iranian SMEs and found that LO has positive effects on both the determination of opportunities and entrepreneurship of a company. Zhu et al. (2019) found that EO is influenced by the organizational learning of a firm, where EO plays a mediating role between the organizational learning and performance of 181 enterprises in the processing and service sectors in China. Thus, there is currently no conclusive association of EO with LO due to the inconsistent empirical evidence. Due to the conflicting empirical results of previous studies, the present study theorizes the particular nature of the concepts and hypothesizes the likely interaction between the two orientations. Researchers have urged for efforts to be made to gain greater insights of the link between EO and the learning process in SMEs (Allameh \& Khalilakbar 2018). Thus, the following hypothesis is suggested:

$\mathrm{H}_{2}$ : Entrepreneurial orientation has a significant effect on the learning orientation of SMEs in Kuwait.

\subsection{The association of Learning orientation with innovation performance}

In the strategic management literature, LO is well-known to be a critical factor in building competitive advantage and ensuring superior business performance (Ratnawati et al., 2018; Zhu et al., 2019). In principle, LO is regarded as the next source of organization's competitive advantage (Zhu et al., 2019), which is the critical element in the success of a company (Tajeddini et al., 2017). The current investigations on the LO-innovation performance interaction have not produced a definitive result on the nature of the relationship (Park et al., 2017; Mahto et al., 2018), and scholars still requesting to integrate mechanism moderating or mediating to better theorization this issue (Jeihoony et al., 2019). Park et al. (2017) argued that the direct effect 
of LO on innovation is contingent upon the extent of the learning orientation practiced by a firm. They suggested that the frequency of interaction moderate the effect on the LO-innovation relation. Mahto et al. (2018) suggested that the gender of the firm owner moderate the LO-innovation relation in SMEs, where a small firm managed by a male owner is less likely to comprehend the significant positive impact of LO on firm innovation. Jeihoony et al. (2019) asserted that, by itself, LO does not result in a high degree of innovativeness in SMEs since they found that just with operation strategy and environmental uncertainty is possible to improve this relationship. On the other hand, Ebrahimi et al. (2018) have shown that LO has no significant effect on performance of SMEs Due to the inefficient structures and policies that adopted by SMEs in Iran. SMEs that do not implement innovation and learning have a small chance of surviving in an increasingly turbulent market climate. Calisir et al. (2013) discovered that common vision and commitment to learning has an insignificant impact on the performance of product innovation. This reinforces the need for more investigation to be done on the influence of LO on the innovation performance of SMEs in countries such as Kuwait. Consequently, the following hypothesis is suggested:

$\mathrm{H}_{3}$ : Learning orientation has a significant effect on the innovation performance of SMEs in Kuwait.

\subsection{The association of Entrepreneurial Orientation, Learning Orientation and Innovation Performance}

Many previous researches have investigated the role of LO as a mediation mechanism on the relationship between EO and performance. For example, Karami and Tang (2018) suggested that EO enhance experiential learning, and aims to take advantage of learning opportunities to gain more knowledge and information, and improve the overall performance of SMEs. Mantok et al. (2019) found that the EO adopted by SMEs is likely to have an indirect effect on business performance by creating and maintaining a conducive learning environment. Rezaei \& Fanak (2019) have proven that organizational learning is able to optimize the effect of EO on firm performance. Aloulou (2018) has highlighted that EO and LO are the determinants of firm performance, where the influence of EO on performance is for the most part indirect and is mediated by LO. Allameh and Khalilakbar (2018) argued that, by itself, EO may not be able to predict the enhanced innovation performance; the researchers have also shown that EO affects organizational learning (OL), which as a consequence has a significant positive impact on innovation performance. Even though previous studies have investigated the impact of EO on innovation performance (e.g., Jalilvand et al., 2018; Genc et al., 2019), the results of these research are not consistent (Kollmann \& Stöckmann, 2014). Thus, there is no research examined whether and how EO affects SMEs innovation performance from the perspective of LO. On the basis of the above reasoning and evidence, this research aims to explore the manner in which EO is integrated with LO to overcome the challenges and identify fruitful opportunities in order to improve innovation performance and achieve sustainability, and thus,

$\mathrm{H}_{4}$ : Learning orientation mediates the association of entrepreneurial orientation with the innovation performance of SMEs in Kuwait.

$\mathrm{H}_{4}$

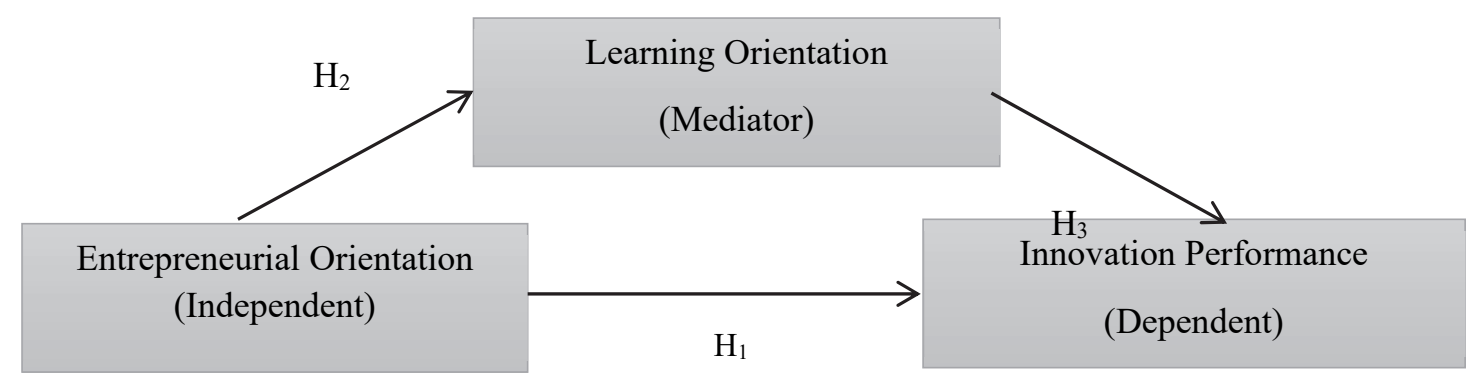

Fig.1. Conceptual model

\section{Methodology, Analysis and results}

This study adopted quantitative methods to examine and test the hypothesis which states that the association of EO with IP is mediated by LO. The target population in the present study includes the leaders, managers and CEOs of SMEs in Kuwait. The structural equation model was used to test the research hypotheses. Smart PLS 3.0 was used to run the model and test the proposed relationship, including the direct and mediated hypotheses. A close ended questionnaire, which contains sections on the demographic information of the respondents and the statements related to the conceptual framework of the study, was administered to gather the data for the study. The subject of the study consists of 221 SMEs in Kuwait. The subjects for the study were selected using a stratified random sampling method. The model's validity and reliability have been assured and the results are presented to support the initial claims. This research paper used Smart PLS 3 to perform the hypotheses testing. The measurement model was assessed to ensure that the model is valid and reliable. The model and item loadings are presented below as an output of Smart PLS. The PLS algorithm was run to assess the validity of the model. The model was assessed based on the convergent validity and discriminant validity. The convergent validity is ensured based on the results of the factor loading, scale reliability (Cronbach's alpha), composite reliability, and average variable extracted (AVE). The recommended minimum value for factor loading is 0.5 for each item, the minimum composite validity is 0.8 , and the minimum value for Cronbach's alpha is 0.7 (Hair et at., 2014). All criteria have been met for the model. 


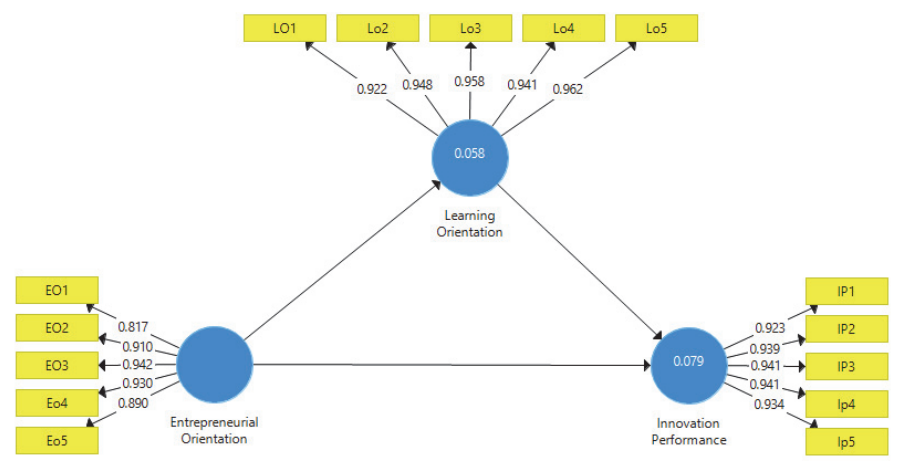

Fig. 2. Measurement Model (Factor Loadings)

Table 1

Convergent validity, Cronbach's alpha, Composite Reliability (CR), AVE

\begin{tabular}{|c|c|c|c|c|c|}
\hline Construct & Item & Loading & Cronbach's Alpha & $\mathrm{CR}$ & AVE \\
\hline \multirow{5}{*}{ Entrepreneurial Orientation } & EO1 & 0.817 & 0.94 & 0.955 & 0.808 \\
\hline & $\mathrm{EO} 2$ & 0.91 & & & \\
\hline & $\mathrm{EO} 3$ & 0.942 & & & \\
\hline & EO4 & 0.93 & & & \\
\hline & EO5 & 0.89 & & & \\
\hline \multirow{5}{*}{ Innovation Performance } & IP1 & 0.923 & 0.96 & 0.972 & 0.876 \\
\hline & IP2 & 0.939 & & & \\
\hline & IP3 & 0.941 & & & \\
\hline & IP4 & 0.941 & & & \\
\hline & IP5 & 0.934 & & & \\
\hline \multirow{5}{*}{ Learning Orientation } & LO1 & 0.922 & 0.97 & 0.977 & 0.896 \\
\hline & $\mathrm{LO} 2$ & 0.948 & & & \\
\hline & LO3 & 0.958 & & & \\
\hline & LO4 & 0.941 & & & \\
\hline & LO5 & 0.962 & & & \\
\hline
\end{tabular}

\subsection{Discriminant Validity}

Table 2 presents the results Heterotrait -Monotrait Ratios between Innovation performance and Entrepreneurial Orientation.

Table 2

Heterotrait-Monotrait Ratio

\begin{tabular}{lcc}
\hline & Entrepreneurial Orientation & Innovation Performance \\
\hline Innovation Performance & 0.225 & 0.236 \\
Learning Orientation & 0.244 & 0.26 \\
\hline
\end{tabular}

The discriminant validity for the model is assessed using the HTMT ratio. This ratio should be less than the benchmark value of 0.85 . The table and graph show that all values are within the set threshold, and thus the discriminant validity of the model is assured.

\subsection{Structure Equation Modelling}

The hypotheses of the model were tested by performing bootstrapping on 5000 samples. The direct and indirect effects were tested to assess the direct and mediated hypotheses (Hair et al., 2014; Soto-Acostaet al., 2016).

Table 3

The results of Direct Effects (Hypotheses 1 to 3) using Path Model (Bootstrapping Results)

\begin{tabular}{llcccc}
\hline Hypothesis & Relationship & Std. Beta & SE & T Statistics & P Values \\
\hline H1: & Entrepreneurial Orientation $\rightarrow$ Innovation Performance & 0.166 & 0.068 & 2.454 \\
H2: & Entrepreneurial Orientation $\rightarrow$ Learning Orientation & 0.014 & 0.241 & 0.067 & 3.609 \\
H3: & Learning Orientation $\rightarrow$ Innovation Performance & 0.191 & 0.067 & 2.847 & 0.000 \\
\hline
\end{tabular}

Table 3 shows the results for the direct hypotheses 1 to 3 . It shows that entrepreneurial orientation has a positive and significant impact on innovation performance with $(\beta=0.166, \mathrm{P}=0.014)$. The impact of entrepreneurial orientation on learning orientation is positive and significant with $(\beta=0.241, \mathrm{P}=0.000)$, and the impact of learning orientation on innovation performance is positive and significant with $(\beta=0.191, \mathrm{P}=0.004)$. Thus, all three direct hypotheses are positive and significant. 


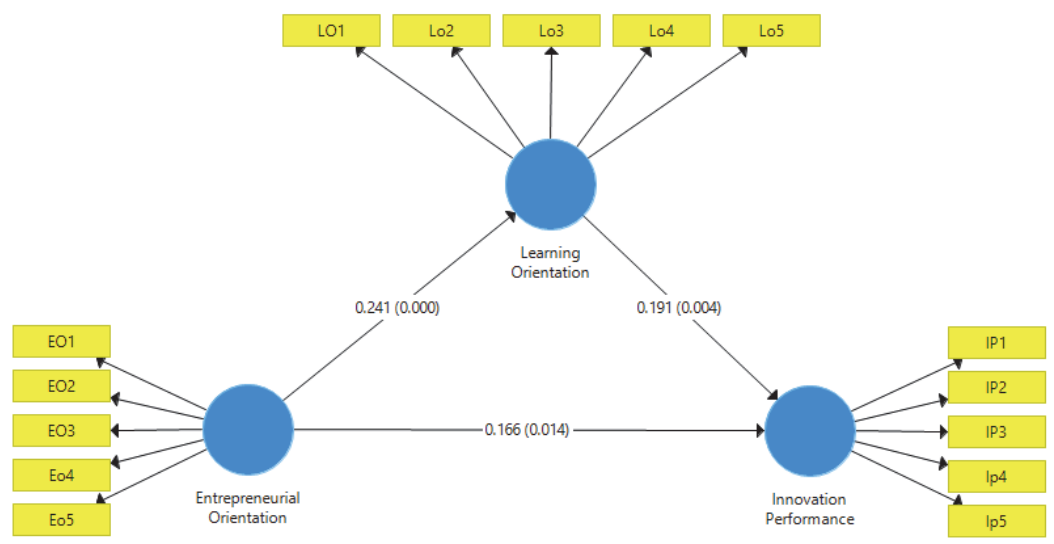

Fig. 3. Path Model (Coefficients and P-values)

Table 4

The results of Indirect Effect/Mediation (Hypothesis 4)

\begin{tabular}{|c|c|c|c|c|c|}
\hline Hypothesis & Relationship & Std. Beta & SE & T Statistics & P Values \\
\hline $\mathrm{H} 4$ & $\begin{array}{l}\text { Entrepreneurial Orientation } \rightarrow \text { Total Learning Orientation } \rightarrow \text { Innovation Perfor- } \\
\text { mance }\end{array}$ & 0.046 & 0.022 & 2.121 & 0.034 \\
\hline
\end{tabular}

The table presenting the results for the mediation analysis shows that entrepreneurial orientation has an indirect relationship with innovation performance through the mediation of learning orientation. The results show a significant mediation effect with $(\beta=0.046, \mathrm{P}=0.034)$.

\section{Discussion}

The major issue with the traditional industries in Kuwait is in advocating the adoption of a new path development (path renewal) and encouraging the industries to have a higher degree of innovativeness and competitiveness despite the low levels of education and competency and the absence of investment in Research \& Development. This problem is an indication that the SMEs lack the absorptive capacity with respect to market and learning orientation (LO). As a consequence, they have limited capability to access and acquire external knowledge, use modern manufacturing equipment, and enter new markets, especially international markets, which is working according to innovated ways and complex methods. This study has discussed the concepts of Entrepreneurial Orientation (EO), Innovation Performance (IP), and Learning Orientation (LO) in the context of Kuwait SMEs. This study assumed that EO has a direct and indirect impact on IP through the mediation of LO. Hence, this study provides the evidence that learning orientation and entrepreneurial orientation are related not only to innovation performance but also to each other; therefore, entrepreneurial orientation leads to learning orientation, and this eventually influence innovation performance. EO is associated with methods, creativity, innovation, practices, and risk-taking in strategic decision-making styles that managers use to act entrepreneurially (Jalilvand et al., 2018; Real et al., 2014), is expected to positively impact innovation performance in SMEs. Thus, the relationship between EO-IP needs to be explored in the context of SMEs in different countries (Zehir et al., 2015). This study responded to the call of (Jalilvand et al., 2018; Zehir et al., 2015) and found strong effect of EO on IP in the context of SMEs in Kuwait. Therefore, the Hypothesis one is confirmed. Hypothesis 2 of this study states that there is a positive relationship between entrepreneurial orientation and learning orientation. In fact, researchers have noted that the process through which LO and EO operate is not a simple one; each construct has a complex relation with performance (Hernández-Linares et al., 2018). through reviewing the literature, the researcher noted that the EO and LO is being closely to each other, Some researchers considered LO as a vital antecedent of EO while other researchers reported that EO is a consequence of LO; in other words, there is little consensus justifying the relationship between the two. For example, Aloulou (2018) investigated 230 Saudi firms and was able to demonstrate a significant relationship between EO and LO. Similarly, Allameh and Khalilakbar (2018) argued that EO has a positive effect on the LO of Iranian SMEs. The results of these studies support the result of hypothesis 2 of the present study. Hypothesis 3 of this study is regarding the relationship between learning orientation and innovation performance. The current investigations on the LOinnovation performance relation have not been able to provide a conclusive result on the nature of the relationship (Park et al. 2017; Mahto et al., 2018) and scholars still requesting to integrate mechanism moderating or mediating to better theorization this issue (Jeihoony et al., 2019). For example, Park et al. (2017) argued that the direct effect of LO on innovation is determined by the extent of a firm's learning orientation. They contended that the frequency of interaction moderated the effect on the relationship of LO with innovation. Similarly, Mahto et al. (2018) suggested that the gender of a firm owner moderate the relationship between the LO and innovation of SMEs, where small firms managed by male owners are less likely to comprehend the highly beneficial effects of LO on firm innovation. The results of the hypothesis testing support the idea that the learning orientation of a firm is positively related with the firm's innovation performance. Mantok et al. (2019) have proven that the EO of an SME is likely to have an indirect impact on business performance by creating and maintaining a conducive learning environment. Rezaei and Fanak (2019) have demonstrated that organizational learning is able to maximize 
the impact of EO on firm performance. Aloulou (2018) highlighted that the firm performance is determined by the firm's EO and LO and the indirect influence of EO on performance is mediated by LO. Allameh and Khalilakbar (2018) argued that, by itself, EO may not be able to predict the enhanced innovation performance; the researchers have also shown that organizational learning (OL) is influenced by EO; in turn OL has a significant positive impact on innovation performance. Although there is previous studies that examine the relationship between EO and IP (e.g., Jalilvand et al., 2018; Genc et al., 2019), But the result still inconclusive (Kollmann \& Stöckmann, 2014). Further, there is lack of studies that investigate whether EO effect SMEs innovation performance when LO plays a mediating role on this relationship. Hence, the hypothesized mediation role of learning orientation in the relationship of entrepreneurial orientation and innovation performance is supported by the literature and the results of the current study.

\section{Conclusion}

The primary aim of the present study was to determine the manner in which learning orientation mediate the relationship of entrepreneurial orientation and firm innovation performance. The conceptual framework in this study was developed based on the findings of previous studies, and the partial least square structural equation modelling (PLS-SEM) was used to test the hypotheses. It is apparent that, in the rapidly changing business environment of today, SMEs are faced with difficult challenges to effectively implement the practices that are frequently used by their larger business rivals. The results of this study suggest that all hypotheses are significant and hence the whole conceptual model is supported by the empirical evidence as well as the existing literature. The present study has discussed the concept of entrepreneurial orientation, innovation performance, and learning orientation in the context of Kuwait SMEs. This study assumed that Entrepreneurial orientation exerts both direct and indirect impact on IP through the mediation of learning orientation. This study used quantitative methods to examine and test the hypothesis that the association of entrepreneurial orientation with innovation performance is mediated by learning orientation. The target population of this study are the leaders, managers and CEOs of Kuwait SMEs. The stratified random sampling was used to select the 221 participants of the study. A structured questionnaire containing close ended questions was used to gather the data. The results of this study have shown that the association of entrepreneurial orientation with innovation performance is partially mediated by learning orientation. These results are congruent with those of the existing body of research.

\section{Future Research}

The context of the present study is limited to Kuwait SMEs. Future studies should be extended to include other Gulf and Arab countries. The results of the present study should be compared with the result of investigations carried out in the Asian region. There may be other factors which moderate the relationship between EO and IP such as market orientation or technological orientation. Future studies could also examine the role of leadership style to determine whether these relationships are affected by different leadership styles.

\section{References}

Alegre, J., \& Chiva, R. (2008). Assessing the impact of organizational learning capability on product innovation performance: An empirical test. Technovation, 28(6), 315-326.

Alhnity, H., Mohamad, A., \& Ishak, A. K. (2016). Impact of entrepreneurial orientation on small business performance: Moderating role of government intervention. International Review of Management and Marketing, 6(7S), 95-100.

Abu-Aisheh, A. A. (2018). Entrepreneurship and Economic Growth: Case of Kuwait. Kuwait Program at Sciences Po Student Paper Award.

Allameh, S. M., \& Khalilakbar, R. (2018). Exploring the antecedents of innovation performance: the roles of entrepreneurial orientation, learning orientation and organisational learning. International Journal of Business Excellence, 14(4), 470485.

Aloulou, W. J. (2018). Examining entrepreneurial orientation's dimensions-performance relationship in Saudi family businesses. Journal of family business management.

Amin, M., Thurasamy, R., Aldakhil, A. M., \& Kaswuri, A. H. B. (2016). The effect of market orientation as a mediating variable in the relationship between entrepreneurial orientation and SMEs performance. Nankai Business Review International.

Anderson, B. S., Covin, J. G., \& Slevin, D. P. (2009). Understanding the relationship between entrepreneurial orientation and strategic learning capability: an empirical investigation. Strategic Entrepreneurship Journal, 3(3), 218-240.

Bouazza, A. B. (2015). Small and medium enterprises as an effective sector for economic development and employment creation in Algeria. International Journal of Economics, commerce and management, 3(2), 1-16.

Beyene, K. T., Shi, C. S., \& Wu, W. W. (2016). Linking culture, organizational learning orientation and product innovation performnace: The case of Ethiopian manufacturing firms. South African Journal of Industrial Engineering, 27(1), 88-101.

Bloch, H., \& Bhattacharya, M. (2016). Promotion of innovation and job growth in small-and medium-sized enterprises in Australia: Evidence and policy issues. Australian Economic Review, 49(2), 192-199. 
Boso, N., Cadogan, J. W., \& Story, V. M. (2012). Complementary effect of entrepreneurial and market orientations on export new product success under differing levels of competitive intensity and financial capital. International Business Review, 21(4), 667-681.

Calantone, R. J., Cavusgil, S. T., \& Zhao, Y. (2002). Learning orientation, firm innovation capability, and firm performance. Industrial Marketing Management, 31(6), 515-524.

Calisir, F., Gumussoy, C. A., \& Guzelsoy, E. (2013). Impacts of learning orientation on product innovation performance. The Learning Organization.

Carayannis, E., \& Grigoroudis, E. (2014). Linking innovation, productivity, and competitiveness: implications for policy and practice. The Journal of Technology Transfer, 39(2), 199-218.

Demircioglu, M. A., \& Audretsch, D. B. (2019). Public sector innovation: the effect of universities. The Journal of Technology Transfer, 44(2), 596-614.

Donate, M. J., \& de Pablo, J. D. S. (2015). The role of knowledge-oriented leadership in knowledge management practices and innovation. Journal of Business Research, 68(2), 360-370.

Ebrahimi, P., Shafiee, B., Gholampour, A., \& Yousefi, L. (2018). Impact of organizational innovation, learning orientation and entrepreneurship on SME performance: The moderating role of market turbulence and ICT. In Competitiveness in Emerging Markets (pp. 447-480). Springer, Cham.

Eshlaghy, A. T., \& Maatofi, A. (2011). Learning orientation, innovation and performance: evidence from small-sized business firms in Iran. European Journal of Social Sciences, 19(1), 114-122.

Fairoz, F. M., Hirobumi, T., \& Tanaka, Y. (2010). Entrepreneurial orientation and business performance of small and medium scale enterprises of Hambantota District Sri Lanka. Asian Social Science, 6(3), 34.

Frank, H., Kessler, A., \& Fink, M. (2010). Entrepreneurial orientation and business performance-a replication study. Schmalenbach Business Review, 62(2), 175-198.

Genc, E., Dayan, M., \& Genc, O. F. (2019). The impact of SME internationalization on innovation: The mediating role of market and entrepreneurial orientation. Industrial Marketing Management, 82, 253-264.

Hair Jr F, Sarstedt, J Hopkins, M \& Kuppelwieser, V. (2014). Partial least squares structural equation modeling (PLS-SEM) An emerging tool in business research. European Business Review, 26(2), 106-121.

Hernández-Linares, R., Kellermanns, F. W., \& López-Fernández, M. C. (2018). A note on the relationships between learning, market, and entrepreneurial orientations in family and nonfamily firms. Journal of Family Business Strategy, 9(3), 192204.

Hisrich, R. D., \& Kearney, C. (2013). Managing innovation and entrepreneurship. Sage Publications.

Huang, K. S., \& Wang, Y. L. (2011, January). Entrepreneurship and Innovation: A review of the theory and literatures. In ECONOMICS, TRADE AND DEVELOPMENT (Vol. 7, pp. 69-73).

Huggins, R., \& Thompson, P. (2015). Entrepreneurship, innovation and regional growth: a network theory. Small Business Economics, 45(1), 103-128.

Jalilvand, M. R., Pool, J. K., Jamkhaneh, H. B., \& Tabaeeian, R. A. (2018). Total quality management, corporate social responsibility and entrepreneurial orientation in the hotel industry. Social Responsibility Journal.

Wonglimpiyarat, J. (2015). Challenges of SMEs innovation and entrepreneurial financing. World Journal of Entrepreneurship, Management and Sustainable Development.

Jeihoony, P., Jabarzadeh, Y., Kumar, V., \& Garza-Reyes, J. A. (2019). The impact of learning orientation on innovation performance: Mediating role of operations strategy and moderating role of environmental uncertainty.

Kajalo, S., \& Lindblom, A. (2015). Market orientation, entrepreneurial orientation and business performance among small retailers. International Journal of Retail \& Distribution Management.

Kakapour, S., Morgan, T., Parsinejad, S., \& Wieland, A. (2016). Antecedents of corporate entrepreneurship in Iran: the role of strategic orientation and opportunity recognition. Journal of Small Business \& Entrepreneurship, 28(3), $251-266$.

Karami, M., \& Tang, J. (2018, July). Entrepreneurial Orientation and SME International Performance. In Academy of Management Proceedings (Vol. 2018, No. 1, p. 10048). Briarcliff Manor, NY 10510: Academy of Management.

Kellermanns, F., Walter, J., Crook, T. R., Kemmerer, B., \& Narayanan, V. (2016). The resource-based view in entrepreneurship: A content-analytical comparison of researchers' and entrepreneurs' views. Journal of Small Business Management, 54(1), 26-48.

Khan, M. W. J., \& Khalique, M. (2014). An overview of small and medium enterprises in Malaysia and Pakistan: past, present and future scenario. Business and Management Horizons, 2(2), 38-49.

Kharabsheh, R., Ensour, W., \& Bogolybov, P. (2017). Learning orientation, market orientation and organizational performance: The mediating effect of absorptive capacity. Business and Economic Research, 7(1), 114-127.

Koch, E. (2011). Challenges to SME Development in Kuwait. UNDP/Kuwait.

Kollmann, T., \& Stöckmann, C. (2014). Filling the entrepreneurial orientation-performance gap: The mediating effects of exploratory and exploitative innovations. Entrepreneurship Theory and Practice, 38(5), 1001-1026.

Kreiser, P. M., Marino, L. D., Kuratko, D. F., \& Weaver, K. M. (2013). Disaggregating entrepreneurial orientation: the nonlinear impact of innovativeness, proactiveness and risk-taking on SME performance. Small Business Economics, 40(2), 273-291.

Kwak, H., Jaju, A., Puzakova, M., \& Rocereto, J. F. (2013). The connubial relationship between market orientation and entrepreneurial orientation. Journal of Marketing Theory and Practice, 21(2), 141-162. 
Le Bas, C., Mothe, C., \& Nguyen-Thi, T. U. (2015). The differentiated impacts of organizational innovation practices on technological innovation persistence. European Journal of Innovation Management.

Lechner, C., \& Gudmundsson, S. V. (2014). Entrepreneurial orientation, firm strategy and small firm performance. International Small Business Journal, 32(1), 36-60.

Lopes, A. P. V. B. V., Kissimoto, K. O., Salerno, M. S., de Carvalho, M. M., \& Laurindo, F. J. B. (2016). Innovation management: A systematic literature analysis of the innovation management evolution. Brazilian Journal of Operations \& Production Management, 13(1), 16-30.

Mahto, R. V., McDowell, W. C., Kudlats, J., \& Dunne, T. C. (2018). Learning orientation and performance satisfaction as predictors of small firm innovation: the moderating role of gender. Group Decision and Negotiation, 27(3), $375-391$.

Mantok, S., Sekhon, H., Sahi, G. K., \& Jones, P. (2019). Entrepreneurial orientation and the mediating role of organisational learning amongst Indian S-SMEs. Journal of Small Business and Enterprise Development.

Miller, D., \& Friesen, P. H. (1982). Innovation in conservative and entrepreneurial firms: Two models of strategic momentum. Strategic Management Journal, 3(1), 1-25.

Oecd, E. (2005). Oslo manual: Guidelines for collecting and interpreting innovation data. Paris 2005, Sp, 46.

Park, C., Oh, C. H., \& Kasim, A. (2017). Market challenges, learning and customer orientation, and innovativeness in IJVs. International Marketing Review.

Polder, M., Leeuwen, G. V., Mohnen, P., \& Raymond, W. (2010). Product, process and organizational innovation: drivers, complementarity and productivity effects. CIRANO-scientific publications $2010 \mathrm{~s}-28$.

Proctor, T. (2018). Creative problem solving for managers: developing skills for decision making and innovation. Routledge.

Ratnawati, S., \& BE, M. FD, \& Wahyono, H.(2018). The role of SMEs' innovation and learning orientation in mediating the effect of csr programme on smes' performance and competitive advantage. Global Business Review, 19(3 suppl), 21-38.

Real, J. C., Roldán, J. L., \& Leal, A. (2014). From entrepreneurial orientation and learning orientation to business performance: analysing the mediating role of organizational learning and the moderating effects of organizational size. British Journal of Management, 25(2), 186-208.

Reguia, C. (2014). Product innovation and the competitive advantage. European Scientific Journal, 1(June), $140-157$.

Renko, M., Carsrud, A., \& Brännback, M. (2009). The effect of a market orientation, entrepreneurial orientation, and technological capability on innovativeness: A study of young biotechnology ventures in the United States and in Scandinavia. Journal of Small Business Management, 47(3), 331-369.

Rezaei, R., \& Amin Fanak, D. (2019). Mediation effect of organizational learning on the relationship between entrepreneurial orientation and organizational performance in the agriculture Jihad Organization of West Azerbaijan Province, Iran. Journal of Agricultural Science and Technology, 21(1), 37-50.

Rhee, J., Park, T., \& Lee, D. H. (2010). Drivers of innovativeness and performance for innovative SMEs in South Korea: Mediation of learning orientation. Technovation, 30(1), 65-75.

Rogers, E.M. (2002). Diffusion of innovations, $5^{\text {th }}$ ed., New York: Free Press

Rubera, G., \& Kirca, A. H. (2012). Firm innovativeness and its performance outcomes: A meta-analytic review and theoretical integration. Journal of Marketing, 76(3), 130-147.

Soto-Acosta, P., Placer-Maruri, E., \& Perez-Gonzalez, D. (2016). A case analysis of a product lifecycle information management framework for SMEs. International Journal of Information Management, 36(2), 240-244.

Jha, S., \& Bhattacharyya, S. S. (2013). Learning orientation and performance orientation: Scale development and its relationship with performance. Global Business Review, 14(1), 43-54.

Tajeddini, K., Altinay, L., \& Ratten, V. (2017). Service innovativeness and the structuring of organizations: The moderating roles of learning orientation and inter-functional coordination. International Journal of Hospitality Management, 65, 100114.

Teece, D.J., (2016). Dynamic capabilities and entrepreneurial management in large organizations: Toward a theory of the (entrepreneurial) firm. European Journal for Economics. 86, 202-216.

Vega-Vázquez, M., Cossío-Silva, F. J., \& Revilla-Camacho, M. Á. (2016). Entrepreneurial orientation-hotel performance: Has market orientation anything to say?. Journal of Business Research, 69(11), 5089-5094.

Yauri, N. M., Koko, M. A., \& Bankanu, M. B. (2008). Micro-finance, small scale enterprises and poverty reduction: Evidence from Sokoto metropolis. Journal of Management Studies, 2(2), 42-56.

Zehir, C., Can, E., \& Karaboga, T. (2015). Linking entrepreneurial orientation to firm performance: the role of differentiation strategy and innovation performance. Procedia-Social and Behavioral Sciences, 210, 358-367.

Zhai, Y. M., Sun, W. Q., Tsai, S. B., Wang, Z., Zhao, Y., \& Chen, Q. (2018). An empirical study on entrepreneurial orientation, absorptive capacity, and SMEs' innovation performance: A sustainable perspective. Sustainability, $10(2), 314$.

Zhu, C., Liu, A., \& Wang, Y. (2019). Integrating organizational learning with high-performance work system and entrepreneurial orientation: a moderated mediation framework. Frontiers of Business Research in China, 13(1), 11.

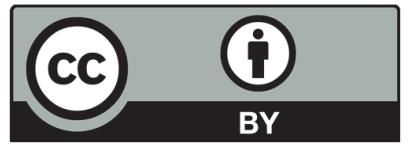

(C) 2020 by the authors; licensee Growing Science, Canada. This is an open access article distributed under the terms and conditions of the Creative Commons Attribution (CC-BY) license (http://creativecommons.org/licenses/by/4.0/). 